\title{
Natural Polymeric Beads for Encapsulation of Stellaria media Extract with Antioxidant Properties
}

\author{
FLORINA MIERE (GROZA) ${ }^{1}$, ALIN CRISTIAN TEUSDEA ${ }^{2}$, VASILE LASLO ${ }^{2}$, LUMINITA FRITEA ${ }^{3}$, \\ LIVIU MOLDOVAN ${ }^{4}$, TRAIAN COSTEA ${ }^{5}$, DIANA UIVAROȘAN ${ }^{3}$, SIMONA IOANA VICAS ${ }^{2 *}$, ANAMARIA PALLAG $^{3}$ \\ ${ }^{1}$ University of Oradea, Doctoral School of Biomedical Science, 1 University Str., 410087, Oradea, Romania \\ ${ }^{2}$ University of Oradea, Faculty of Environmental Protection, 26 Gen. Magheru Str., 410048 Oradea, Romania \\ ${ }^{3}$ University of Oradea,Faculty of Medicine and Pharmacy,10 1 Decembrie Sq., 410087, Oradea, Romania \\ ${ }^{4}$ University of Oradea, Faculty of Electrical Engineering and Information Technology, 1 University Str., 410087, Oradea \\ ${ }^{5}$ University of Oradea, Industrial Engineering Doctoral School, 1 University Str., 410087, Oradea, Romania
}

Natural polymers are biodegradable and biocompatible and can be used as carriers of pharmaceutical active compounds, with good results for the enhancement of their stability characteristics.Plant extracts of the Cariophyllaceae family are of great interest due to antioxidant, anti-inflammatory, carminative, anticancer, antibacterial, antifungal, antiviral properties, and more recently, the ability to inhibit intestinal carboxylation and reduce obesity by complex mechanisms. The aim of our study was tocharacterize the Stellaria media aqueous extract from the point of view of total polyphenols (using Folin-Ciocalteu method) and antioxidant capacity, as well as the efficiency of inclusion of Stellaria extract in calcium chloride alginate beads by two different methods. In the same time, the size of alginate microcapsules was investigated along with the released efficiencyfrom the polymeric matrix in different biological fluids.Two different methods for encapsulation of Stellaria media extract were developed in this work, using calcium alginate beads. Encapsulating efficiency shows a better approach within the method in which the extract was in situ encapsulated in "pearls"-shaped beads

Keywords: Stellaria media, alginate, antioxidant capacity (DPPH, FRAP, TEAC, CUPRAC), simulated biological fluids

Natural polymers are biodegradable and biocompatible and can be used as carriers of pharmaceutical active compounds, with good results for the enhancement of their stability characteristics [1]. Alginate, the salt of alginic acid, is alow-cost and biodegradable polymer which consists of $\alpha$-L-guluronic acid and $\beta$-D-mannuronic acid, their relative proportion ratio being related to the biofunctionalproperties of alginic acid [2].

The use of alginate matrix has a number of advantages including: controlled release of active compounds, avoidance of incompatibilities, release to target, improved compound stability, improved bioavailability [3, 4].Alginate has been referred to as 'hydrogels' due to its swelling capability in water which allows them to exhibit an environment that resembles the highly hydrated state of natural tissues, being also stable both chemically and thermally.

One of the most used alginate hydrogels is produced by cross-linking reaction with calcium chloride or magnesium chloride or a mixture of calcium and magnesium chloride in which a series of herbal extracts can be incorporated: extracts from Eurycomalongifolia, Piper sarmentosum, Labisia pumila, Andrographis paniculata, Orthosiphonstamineus and Centella asiatica [3], pomegranate extract [5], black carrot [6], Clitoria ternate [7, 8]. Microencapsulation is an effective method to protect bioactive components, preserve their stability during processing and storage and prevent undesirable interactions with food matrix $[9,10]$.

Plant extracts of the Cariophyllaceae family are of great interest due to antioxidant, anti-inflammatory, carminative, anticancer, antibacterial, antifungal, antiviral properties, and more recently, the ability to inhibit intestinal carboxylation and reduce obesity by complex mechanisms [3, 9] .

The extract from Stellaria media has been studied to date by Chidrawar., [11], demonstrating good activity against obesity induced by progesterone consumption. It has been used also in folk medicine for the treatment of gallstones $[8,10,12,13]$.

The composition rich in polyphenols, saponosides, vitamin C, silicon, mucilage and carotene [12] makes the extract from $S$. media to have intense antioxidant activity. However, this activity can be influenced by many

*email: sim_vicas@yahoo.com, Phone: +400745259235 
factors such as temperature, $\mathrm{pH}$, presence or absence of light, storage conditions [3,14,15]. Also, the antioxidant activity of the extract can be influenced by factors related to the internal body's fluids when administered orally: gastric fluid or intestinal fluid $\mathrm{pH}$ value. Thus, in order to avoid these inconveniences, the natural extracts are incorporated into alginate microcapsules (pearls).

The aim of our study was to characterize the Stellaria media aqueous extract from the point of view of total polyphenols and antioxidant capacity, as well as the efficiency of inclusion of $S$. media extract in calcium chloride alginate beads by two different methods. In the same time, the size of alginate microcapsules was investigated along with the released efficiency from the polymeric matrix in different biological fluids.

The main purpose is to highlight the most advantageous encapsulation method of $S$. media extract using alginate matrix and to monitor the degradation process during the controlled release of the extract.

\section{Experimental part}

Materials and methods

Sodium Alginate (AppliChem), Calcium Chloride (Bucharest Reagent), Gallic Acid (Sigma Life Science), Folin-Ciocalteu Reagent (Merck), Sodium Carbonate (Ingen Laboratory), 2,2-Diphenyl-1-picrylhydrazyl (DPPH), ABTS (2,2'-azino-bis(3-ethylbenzthiazoline-6-sulfonic acid) diammoniumsalt), Neocuproin Hemihydrat (ROTH), Trolox (6-hydroxy-2,5,7,8-tetramethylchroman-2-carboxylic acid) were purchased from Sigma Aldrich (St. Louis, MO, USA). All the chemical reagents were analytical grades.

\section{Preparation of Stellaria media extract}

The S. media plant was harvested on the shores of Crisul Repede (Bihor County) at a temperature of $11^{\circ} \mathrm{C}$. The entire plant was harvested, the total quantity being $413.5 \mathrm{~g}$ of fresh vegetable product. The plant was dried in the oven at $75^{\circ} \mathrm{C}$ until a constant mass was obtained. This high drying temperature has been chosen because it inhibits the enzymes that are possible involved in the degradation of active compounds. Thus, after drying, $41 \mathrm{~g}$ dry product has been obtained, which means that the harvested plant had almost $90 \%$ water content. The dry plant and ethanol 70\% were mixed in a 1: $20(\mathrm{w} / \mathrm{v})$ ratio. The mixture was maintained for 24 hours under continuous stirring in the dark. It was then filtered and the solvent was evaporated on a rotavapor for 1 hour at $44^{\circ} \mathrm{C}$ and $92 \mathrm{rpm}$. After the complete evaporation of the alcohol, we obtained the aqueous extract, which was frozen at $-80^{\circ} \mathrm{C}$. After freezing, the sample was lyophilized and characterized in terms of the active principles composition. The total content of total polyphenols was characterized by Folin-Ciocalteu method, while the antioxidant capacity was determined by DPPH, FRAP, TEAC and CUPRAC method.

\section{DPPH method}

Radical scavenging capacity of Stellaria media extract using the stable 2-picryl-hydrazyl-hydrate (DPPH) radical was determined according to the method of Brand Williams [16], with some modifications. The reduction of DPPH was monitored spectrophotometrically at $517 \mathrm{~nm}[17,18]$ using a Shimadzu mini UV-Vis spectrophotometer.

A volume of $100 \mu \mathrm{l}$ of the aqueous extract was mixed with $2800 \mu$ freshly prepared methanolic DPPH solution $(80 \mu \mathrm{M})$. After 30 minutes incubation in darkness, at room temperature the absorbance of sample was measured at $517 \mathrm{~nm}$ against a blank of distillated water. The antioxidant capacity was calculated by the equation 1 [17]:

where:

$$
\% \text { Radical Scavenging Activity }(\mathrm{RSA})=\left[\left(\mathrm{A}_{0}-\mathrm{A}_{1}\right) / \mathrm{A}_{0}\right] \times 100
$$

$\mathrm{A}=$ was the absorbance of DPPH free radical solution in methanol

$\mathrm{A}_{1}$ the absorbance of the sample.

The experiment was performed in triplicate and the results are expressed as average values with standard deviation.

\section{FRAP method (Ferric Reducing Antioxidant Power)}

The FRAP method is also based on spectrophotometric measurement in order to evaluate the antioxidant power of Stellaria media extract. The antioxidant capacity is evaluated based on the reduction of $\mathrm{Fe}^{3+}$ from tripyridyltriazine $\mathrm{Fe}(\mathrm{TPTZ})^{3+}$ complex, to the blue coloured complex-Fe(TPTZ) ${ }^{2+}$ in acidic medium $[19,20]$.

The stock solutions consist in $300 \mathrm{mM}$ acetate buffer; $270 \mathrm{mgFeCl} \mathrm{H}_{3} \cdot 6 \mathrm{H}_{2} \mathrm{O}$ dissolved in $50 \mathrm{~mL}$ distillated water, $150 \mathrm{mg}$ TPTZ and $150 \mu \mathrm{LHCl}$, dissolved in $50 \mathrm{~mL}$ distillated water. The working FRAP solution was 
freshly prepared by mixing acetate buffer, $\mathrm{FeCl}_{3} \cdot 6 \mathrm{H}_{2} \mathrm{O}$ solution and TPTZ solution $(10: 1: 1$, v/v/v). Stellaria media extract $(100 \mu \mathrm{l})$ were allow to react with $500 \mu \mathrm{l}$ FRAP working solution and $2 \mathrm{ml}$ distilled water, for $1 \mathrm{~h}$, in the dark. The final product (ferrous tripyridyltriazine complex) was quantified by VIS absorption at $595 \mathrm{~nm}$. The results were expressed in $\mu$ molTrolox equivalent (TE)/g dw (dry weight).

TEAC method (Trolox equivalent antioxidant capacity)

The TEAC method (Trolox equivalent antioxidant capacity) is based on the ability of antioxidants to reduce the life of a cation radical (ABTS ${ }^{+}$), a green blue chromophore absorbing at $734 \mathrm{~nm}$. Shortly, the cation radical was produced by reacting the ABTS solution $(7 \mathrm{mM})$ with $2.45 \mathrm{mM}$ potassium persulfate, keeping the mixture in the dark at room temperature for 15 hours.

ABTS stock solution was diluted with ethanol in order to obtain an absorbance of $0.70 \pm 0.02$ at $734 \mathrm{~nm}$. After addition of $100 \mu \mathrm{l}$ extract to $2.9 \mathrm{ml}$ of diluted ABTS stock solution, the antioxidant capacity was monitored spectrophotometrically at $734 \mathrm{~nm}$. The results were expressed in $\mu \mathrm{molTE} / \mathrm{g} \mathrm{dw}[21,22,23]$.

\section{CUPRAC method (Cupric Reducing Antioxidant Capacity)}

The method consist in combination of antioxidant extract with a copper (II) chloride solution $\left(1 \times 10^{-2} \mathrm{M}\right)$, a neocuproine (2.9-dimethyl-1, 10-phenantroline) alcoholic solution $\left(7.5 \times 10^{-3} \mathrm{M}\right)$ and an ammonium acetate aqueous buffer $(\mathrm{pH} \mathrm{7)}$, and subsequently measuring the absorbance at $450 \mathrm{~nm}$ after 30 minute. Shortly the method was performed by adding $1 \mathrm{ml} \mathrm{CuCl}_{2}$ solution, $1 \mathrm{ml}$ Neocuproine solution, $1 \mathrm{ml}$ ammonium acetate buffer, $100 \mu \mathrm{l}$ extract followed by water such that to make the final volume $4.1 \mathrm{ml}$. The results were expressed in $\mu \mathrm{mol} \mathrm{TE} / \mathrm{g} \mathrm{dw}[21]$.

\section{Preparation of alginate beads}

Two different methods were applied for preparation of alginate beads encapsulating $S$. media extract:

Method I (M1): The preparation of alginate beads was made according to the working method described by Li et al., 2019 [24] with some modifications. 2 grams of sodium alginate was dissolved in $100 \mathrm{ml}$ of distilled water. This mixture was stirred continuously with the magnetic stirrer until a viscous solution was obtained. Separately, $26.5 \mathrm{mg}$ of the lyophilized plant extract was solubilized in $25 \mathrm{ml}$ of distilled water and sonicated for 30 minutes. Using a needle syringe, the mixture was added dropwise over a $4 \%$ calcium chloride solution (fig.1).The resulting beads were filtrated, washed with distilled water 3 times and dried for 24 hours, at room temperature.

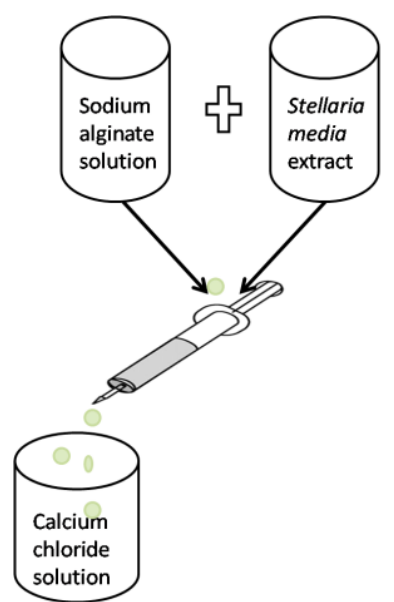

Fig.1. M1 method to obtain alginate beads encapsulating S. media extract.

Method II (M2): This method has been developed by Chan et.al, (2010) [3] and consist in reversing certain stages of the first method. The aqueous solution of sodium alginate was dripped in $4 \%$ calcium chloride, resulting empty beads, which were dried at room temperature for 24 hours. Then, $40 \mathrm{mg}$ of dry empty alginate beads were placed in a cylinder and $2 \mathrm{ml}$ of the aqueous extract was added dropwise with a syringe. After 1 hour in the dark, the mixture was filtrated (fig.2). 
$(2)$

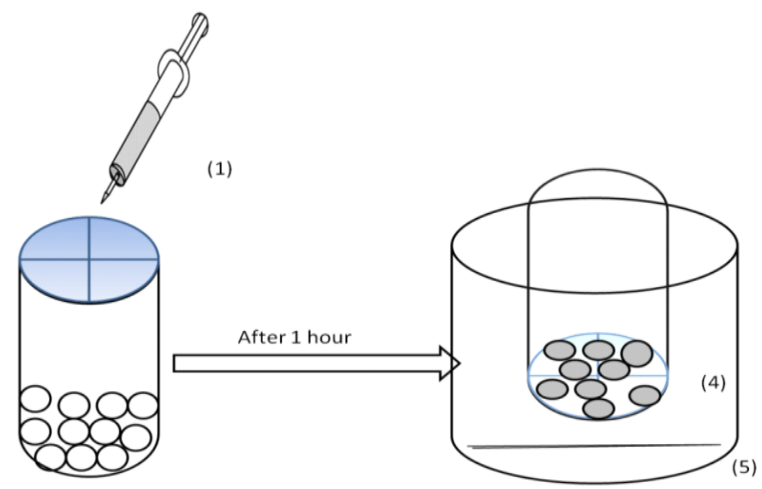

Fig.2. M2 method for obtaining alginate beads with $S$. media extract.

(1)-syringe containing $S$. media extract; (2)-filter; (3)- empty alginate beads;

(4)- alginate containing $S$. media extract; (5)- free $S$. media extract (not included in alginate beads).

Alginate forms readily a gel structure in the presence of divalent ions such as $\mathrm{Ca}^{2+}, \mathrm{Ba}^{2+}$ and $\mathrm{Sr}^{2+}$ via ionic cross-linking (fig.3).
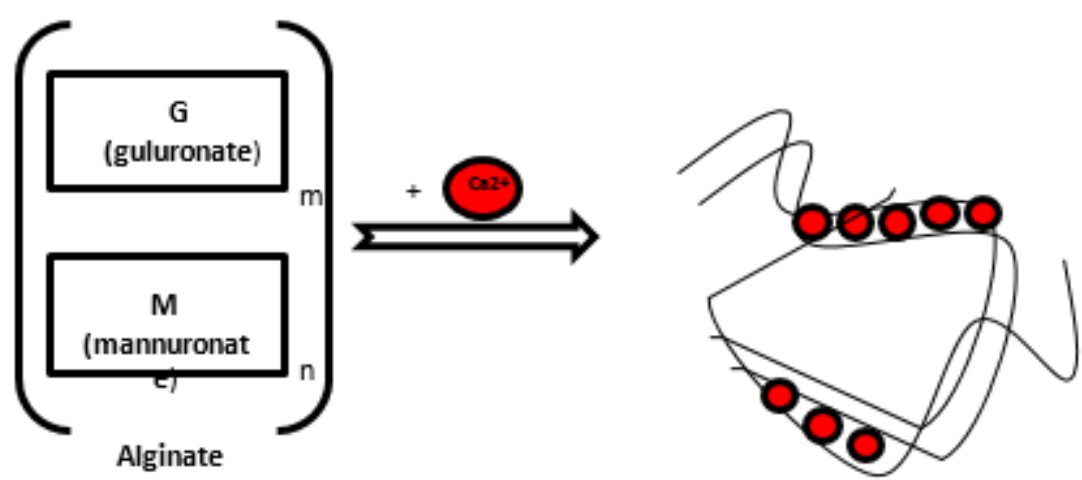

Calcium cross-linking of

Alginate bead

Fig.3. Calcium cross-linking alginate beads

\section{Results and discussions}

Microscopic characterisation of alginate beads

Both Scanning Electron Microscopy (SEM) and optical microscopy were applied in order to evaluate the size and shape of alginate beds with $S$. media extract, obtained by the above mentioned methods. For SEM investigations (with LEO 438 VP SEM microscope) the samples were stacked on a double-sided tape of carbon, fixed on a metal support. The optical images were recorded with Canon CanoScan 9000F Solution device. In order to get a better contrast, the scanned images were taken in transmitted light mode, rather than usually reflected light, at 9600dpi optical resolution (1 pixel $=2.645$ microns). A comparison was made between the results obtained from both preparation methods.

\section{Incorporation efficiency (EE\%)}

EE\% was calculated by determining the total content of polyphenols in initial aqueous extract, respectively in the extract contained in the beads. Within the first preparation method (M1), 5\% sodium citrate was used to dissolve the alginate matrix, and subsequently, Folin-Ciocalteu method was used to determine the total polyphenol content from the supernatant, upon centrifugation. The following mathematical formula was used in order to calculate the incorporation efficiency, equation 2 [7]:

$$
E E(\%)=\frac{T P C e \times 100}{T P C i}
$$


Where: TPCe is the total phenol content encapsulated in beads,

TPCi is the total phenol content in the initial extract solution used for the encapsulation process.

Within the second preparation method (M2), the measurement of total of polyphenols in the initial plant extract, respectively the free extract in the filtrate (obtained after the filtration of the alginate beads) was performed. The total encapsulated extract can be simply calculated by the difference between the initial concentration of the extract and that of the filtrate. Subsequently, the formula (2) was applied [7].

In vitro profile release of Stellaria media extract in simulated biological fluids

In order to determine the release profile of $S$. media extract from alginate beads prepared according to the above methods, a simulated fluid was prepared and the release was monitored in two phases: stomach phase (0$180 \mathrm{~min}$ ) and small intestine phase (180-400 $\mathrm{min})$. Simulated fluids were prepared according to literature [24, 25].

The gastric fluid was prepared from a solution of hydrochloric acid, the $\mathrm{pH}$ being adjusted to 1.2 with $0.1 \mathrm{M}$ sodium hydroxide.

The intestinal fluid was prepared using sodium chloride and HEPES solution, by adjusting the $\mathrm{pH}$ to 6.5 with $0.1 \mathrm{M}$ sodium hydroxide solution.

$0.1 \mathrm{~g}$ alginate beads were weighed in order to monitor the release process in $20 \mathrm{~mL}$ simulated fluids, at different time intervals. The beads were maintained in gastric fluid for 60,120 and 180 minutes, and then transferred to the intestinal fluid, where they were maintained for another 60, 120, 180 and 240 minutes. The content of total of polyphenols in simulated fluids was determined spectrophotometrically. In the same time, the released extract was quantitatively assessed from UV spectra in the range 200-340 nm (using Shimadzu UVVIS 1700 spectrophotometer series PharmaSpec, Shimadzu Japan). The absorbance at 268 and $327 \mathrm{~nm}$ were used in order to calculate the concentration of released extract in biological fluids. Moreover, an optical scanning was performed after in vitro passage through the simulated fluids, at the respective time intervals.

\section{Statistical analysis}

The samples obtained using two different preparation methods were analysed in duplicates. The experimental data were subjected to the following statistical analysis:

Two-way analyse of variance (ANOVA, $\mathrm{P}=0.05$ ) for the assessment of extract released in gastric fluid

Three-way analyse of variance (ANOVA, $\mathrm{P}=0.05$ ) for the assessment of extract released in intestinal fluid.

In both cases, the means were compared by post-hoc Tukey's test $(\mathrm{P}=0.05)$.

The analysed factors within gastric fluid were: Treatment (with M1 and M2 levels according to the preparation method) and Time (with GF1h, GF2h and GF3h levels denoting the encountered release time of the extract). The analysed factors within intestinal fluid were: Treatment (with M1 and M2 levels according to the preparation method), and Time (with I1h, I2h, I3h and I4h levels denoting the time interval monitoring the release process). The univariate statistical analysis was performed with the Minitab 19 (Minitab Inc., Coventry CV3 2TE, UNITED KINGDOM) statistical software.

Antioxidant capacity of Stellaria media extract by Folin-Ciocalteu, DPPH, FRAP, TEAC and CUPRAC methods

Table 1 summarize the antioxidant capacity of $S$. media extract, determined by different methods. The results show the total content of polyphenols which is of primary importance in the antioxidant capacity. The investigation of Sarmah et al. [25] suggested that the major source of antioxidant capacity of S. media may be from phenolic compounds. Others authors [26] also support the use of $S$. media as a natural antioxidant source.

Table 1

TOTAL POLYPHENOLS OF STELLARIA MEDIA EXTRACT AND ITS ANTIOXIDANT CAPACITY EVALUATED BY FOUR DIFFERENT METHODS

\begin{tabular}{|l|l|l|l|l|}
\hline $\begin{array}{l}\text { Total polyphenols } \\
\mathrm{mgGAE} / \mathrm{g} \mathrm{dw}\end{array}$ & $\begin{array}{l}\text { FRAP } \\
\mu \mathrm{mol} \mathrm{TE} / \mathrm{g} \mathrm{dw}\end{array}$ & $\begin{array}{l}\text { CUPRAC } \\
\mu \mathrm{molTE} / \mathrm{g} \mathrm{dw}\end{array}$ & $\begin{array}{l}\text { TEAC } \\
\mu \mathrm{molTE} / \mathrm{g} \mathrm{dw}\end{array}$ & $\begin{array}{l}\text { DPPH } \\
(\boldsymbol{\%})\end{array}$ \\
\hline $19.15 \pm 1.13$ & $27.76 \pm 11.22$ & $0.29 \pm 0.035$ & $0.60 \pm 0.034$ & $78.94 \pm 2.35$ \\
\hline
\end{tabular}




\section{Morphological features of alginate beads with Stellaria media extract}

Alginate beads were subjected to SEM analysis and optical scanning analysis procedures, in order to emphasize their shape and size. It can be noticed that the empty beads have the same shape as the beads containing the plant extract, obtained by Method 1 or 2, with approximately spherical shape. However, the presence of some diminutive depths is observed, which can be interpreted as the penetration of the extract from the $S$. media. It is observed that by M1 those reliefs are filled with extract (fig.4). Instead, in the case of M2 the surface of alginate beads are coated with the extract. The optical scanning provides a better overview of the extract encapsulation effect, compared to SEM images, because the extract is highlighted with green colour, located inside the beads (M1 method), or at the outer-shell (M2 method) when compared to the control beads (fig.5).

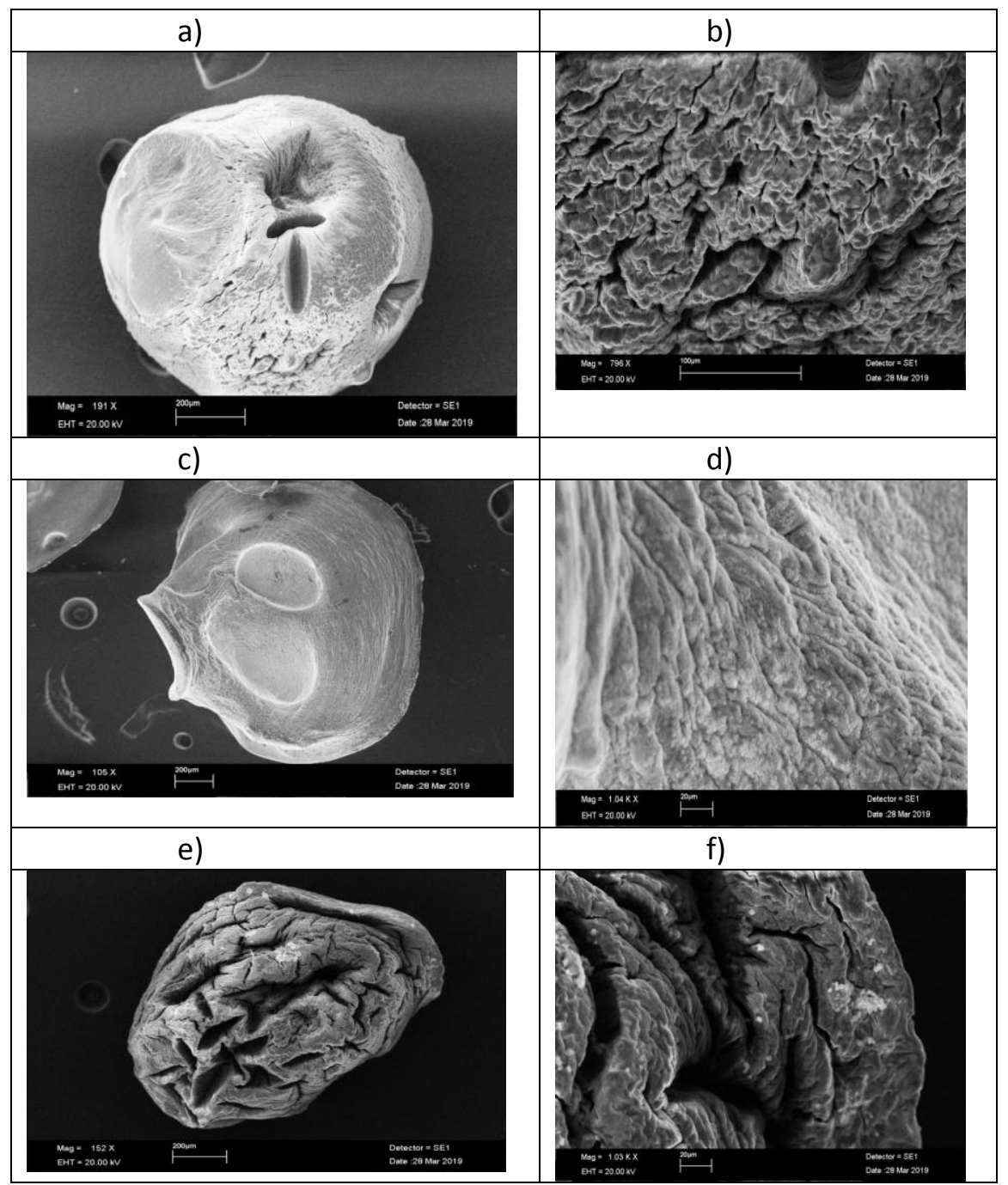

Fig.4. SEM morphological features of empty alginate beads (a,b) and the beads incorporating S. media extract obtained by M1 method (c,d) respectively by M2 method (e,f) with different magnifications

In fig.4 (b, d. f) it can be noticed the nanostructured details of the alginate beads surface.

Comparing the optical images in fig. 5 it can be noticed a better extract incorporation using method M1, as the green colour denotes the chlorophylls pigments in the $S$. extract. With respect to the M2 method, the extract was adsorbed mainly on the surface of the beads, as evidenced by the green colour of the contour. 


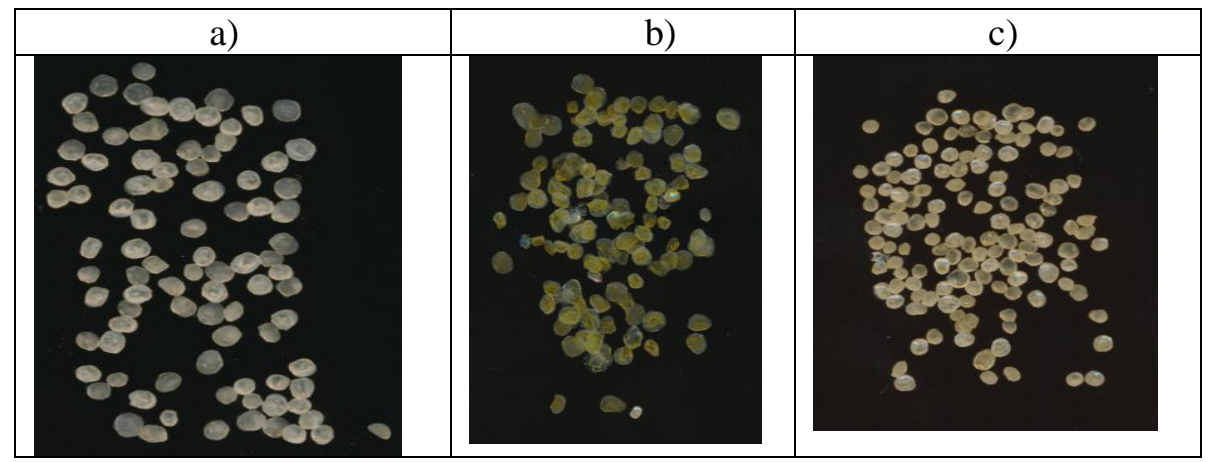

Fig.5. Optical microscope images of empty alginate beads (a), alginate beads obtained by M1 method (b) respectively $\mathrm{M} 2$ method (c)

The particle size (spherical shape) is between $746 \mu \mathrm{m}$ and $857 \mu \mathrm{m}$ approximately, as can be noticed in fig. 6 .

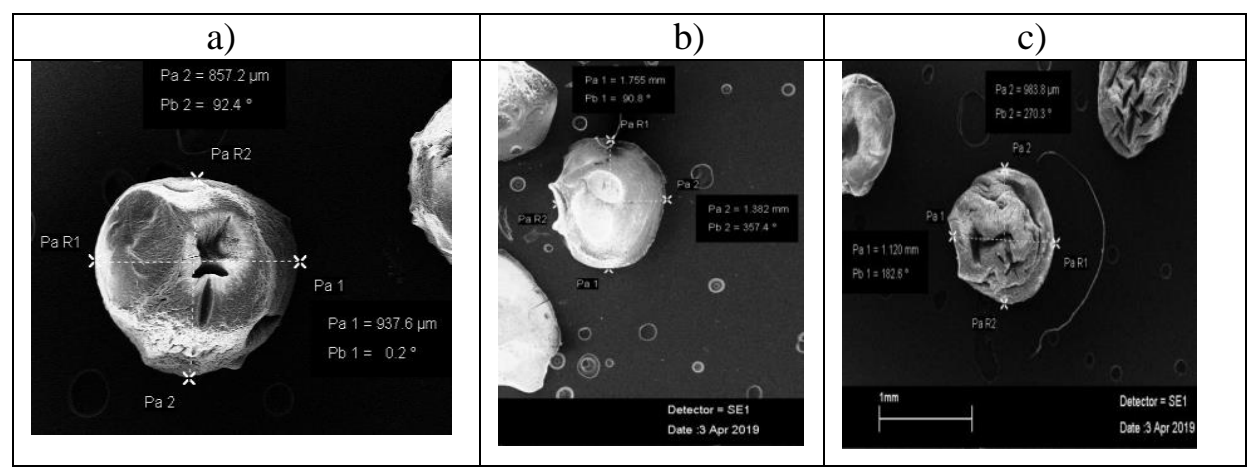

Fig.6. The size of alginate beads measured by SEM: a) empty beads; b) alginate beads M1 method; c) alginate beads M2 method.

Incorporation efficiency (EE\%) of Stellaria media extract in alginate beads and in vitro profile release

The efficiency of encapsulation was calculated accordingly to the method M1 and M2 described for encapsulating the $S$. media extract. $92.47 \%$ encapsulation efficiency was obtained using M1 method, while only $52.43 \%$ was achieved for M2 method. Each method may have advantages and shortcomings depending on the pharmaceutical purpose.

The results obtained by both methods are comparable to those obtained so far in the literature. For example, $74 \%$ encapsulation efficiency of Clitoria ternatea extract in alginate microcapsules was achieved [8], while 70\% efficiency of Stevia rebaudiana encapsulation in alginate beads was obtained [25].

\section{In vitro release of Stellaria media extract in simulated body fluids}

The obtained results allowed us to evaluate the most effective encapsulation method and especially the demonstration of a release to the target.

One can observe that alginate beads are gastroresistant, as the matrix release only a small quantity of $S$. extract in simulated gastric fluid, while retaining the extract until the gradual delivery in intestinal fluid, according to the fig.7. Regardless to the treatment (M1, M2), after passing through the gastric fluids, it can be observed that the residence time in the gastric fluid does not significantly influence the release of the embedded extract. Gastroresistant alginate beads are advantageous because the extract release will happened in the intestine, where it absorbs. 


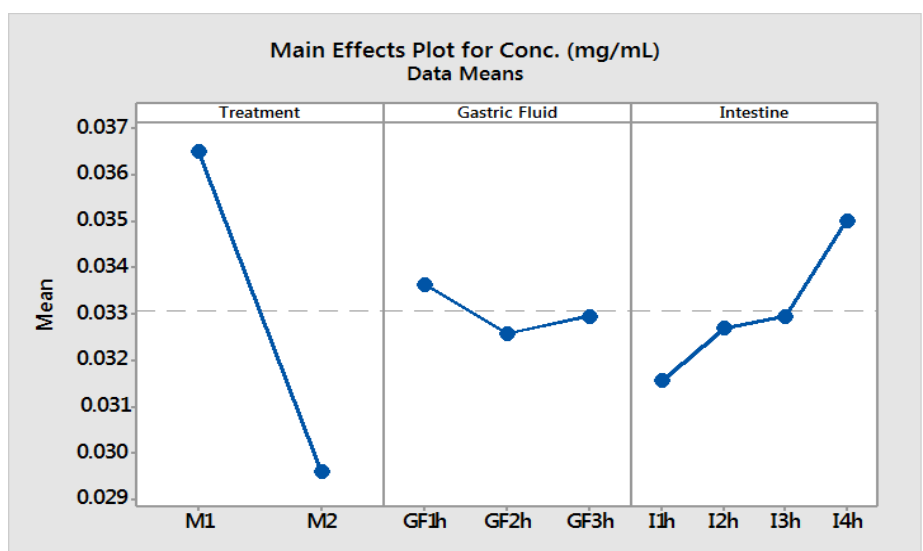

Fig.7. S. media extract release simulated fluids, after different time intervals, regardless to the methods M1 and M2.

A comparison was made with respect to the release profile in simulated gastric fluid, by M1 and M2 methods. According to fig.7 it can be observed that M1 method is more efficient that M2, which is due to the in situ mechanism of encapsulation, respectively surface adsorption of the extract. Accordingly, the quantitative results of release extract are completely different, probably influenced by the nanostructured texture of the alginate beads, as can be seen in the SEM images. So, M1 is more sensitive than M2, the amount of released extract in the gastric fluid being $26 \%$ higher comparing M2 (fig.8).

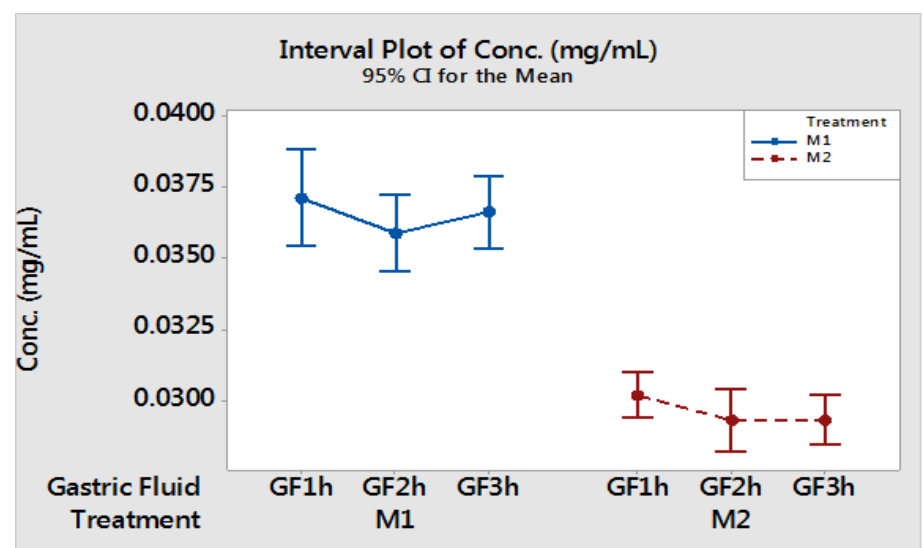

Fig.8.Comparison between M1 and M2 methods with respect to profile release in gastric fluid

Regarding the in vitro release into the intestinal fluid of the $S$. media extract, it was observed using ANOVA statistics,that the best release was obtained within M1method after 4 hours, according to fig.9. Overall, in intestinal fluid, M2 method is less efficient with respect to $S$. media extract release, in the same experimental conditions. In this case, the best release occurs after 1 hour residence time in stomach, followed by 4 hours in the intestine.

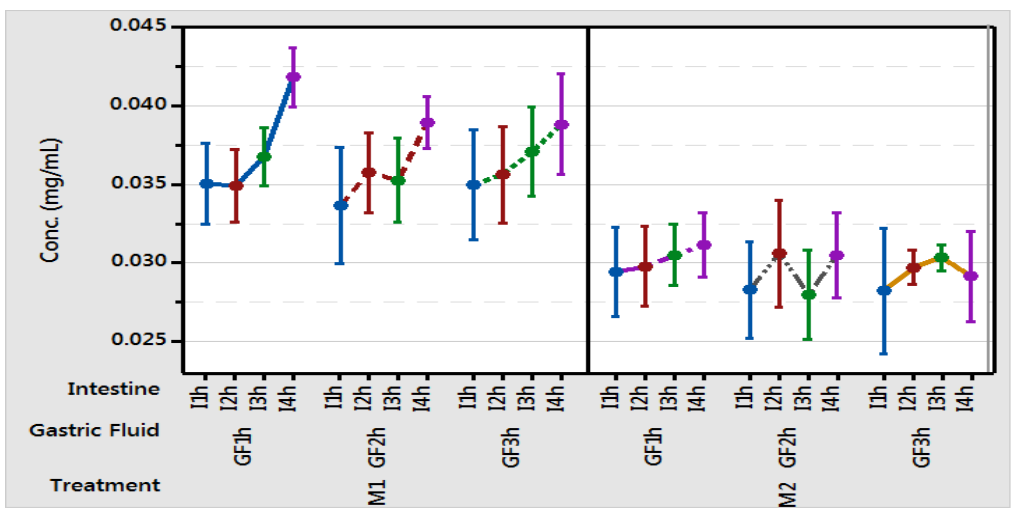

Fig.9.Comparison between M1 and M2 methods with respect to profile release in intestinal fluid 


\section{Conclusions}

Two different methods for encapsulation of $S$. media extract were developed in this work, using calcium alginate beads. The antioxidant properties of the extract were demonstrated by different techniques such as DPPH, FRAP, ABTS and CUPRAC. Encapsulating efficiency shows a better approach within M1 method in which the extract was in situ encapsulated in "pearls"-shaped beads. The morphological details of the beads were investigated by SEM and optical microscopy, evidencing a spherical shape with nanostructured surface, along with the extract accumulation inside, respectively on the surface of alginate layer. The release profile investigated in simulated fluids allowed a comparison between the two methods, taking into account the pharmaceutical purpose.

Acknowledgements: The author (Miere (Groza) Florina) thanks University of Oradea, Doctoral School of Biomedical Science, for providing assistance.

\section{References}

1.BOGDAN, M., ENDRES, L., PASCA, B., TIT, D.M., UIVAROSAN, D., COPOLOVICI, D.M., ALEYA, L., BUNGAU, S., Mat. Plast, 56, no.1, 2019, p. 133.

2.RIJO, P., MATIAS, D., FERNANDES, A.S., SIMÕES, M.F., NICOLAI, M., REIS C.P. Polymers, 6, 2014, p. 479.

3.CHAN, E-S., YIM, Z-H., PHAN, S-H., MANSA, R. F., RAVINDRA, P. Food Bioprod Process, 88, 2010 , p. 195.

4.ZHANG, J., DAUBERT, C.R., FOEGEDING E. A. J.Food Sci., 70 (7), 2005, p.425.

5.ZAM, W., Hindawi Journal of Food Quality, Article ID 8192964, 2019, p.1.

6.ERSUS, S., YURDAGEL U. J.Food Eng., 80 (3), 2007, p.805.

7.PASUKAMONSET, P., ORAN KWON, O., ADISAKWATTANA, S. Food Hydrocolloids, 61, 2016, p. 772.

8.PORNTIP, P., KWON, O., ADISAKWATTANA, S., Food Hydrocolloids, 61 2016, p.772.

9.MARIAN, E., JURCA, T., VICAȘ, L., KACSO, I., MICLĂUȘ, M., BRATU, I. Rev. Chim. (Bucharest), 62, no. 112011 p. 1065.

10.IOVA, A., MICLE, O., VICAȘ, L., MICLE, L., IOVA, S., MUREȘAN, M., IONIȚĂ, C.A. Farmacia, 62 (3),2014, p. 546.

11.CHIDRAWAR, V.R., PATEL, K.N., SHETH, N.R., SHIROMWAR, S.S., TRIVEDI, P. Ayu. 32(4), 2011, p.576.

12.CAVALU, S., DAMIAN, G., DANSOREANU, M. Biophys. Chem., 99 (2), 2002, p.181.

13.NEERJA, R., VASUDEVA N., SHARMA S.K., CAM, 12, 2012, p.145.

14.CAVALU, S., POPA, A., BRATU, I., BORODI, GH., MAGHIAR, A. Biol. Trace Elem Res, 168 (2), 2015 p. 311.

15. ARORA, D., SHARMA, A. J. Pharm. Sci. \& Res.,4 (5), 2012, p. 1819.

16.BRAND-WILLIAMS W., CUVELIER, M.E., BERSET, C., LWT-Food Sci. Technol., 28, 1995, p. 25.

17.POP (CUCEU), A-V., TOFANĂ, M., SOCACI, S.A., POP,C., ROTAR, A.M. NAGY, M., SALANŢĂ, L. Bull. Univ. Agric. Sci. Vet. Med. Cluj-Napoca, Food Sci. Technol, 73(1), 2016, p.14.

18.JURCA, T., VICAȘ, L., MARIAN, E., VICAȘ, S., MUREȘAN, M. FARMACIA, 64 (1), 2016, p.135.

19.BENZIE I.F., STRAIN, J.J. Anal. Biochem., 239, 1996, p. 70.

20.CAVALU S., PROKISCH J., LASLO V., VICAS S. IET Nanobiotechnology, 11 (4), 2017, p.426.

21.DOBJANSCHI, L., FRITEA, L., PATAY, E.B., TAMAS, M., PAK. J. PHARM, 32 (4), 2019, p.1571.

22.ANTONESCU (MINTAS), I.A., JURCA, T., GLIGOR, F., CRACIUN, I., FRITEA, L., PATAY, E.B., MURESAN, M., UDEANU, D.I., IONUTA, C.A., ANTONESCU, A., BODOG, F., Farmacia, 67, 2019, p 146.

23.JURCA, T., VICAȘ, L., TÓTH, I., BRAUN, M., MARIAN, E., TEUSDEA, A.C., VICAȘ, S.I., MUREȘAN M., Farmacia, 64 (4), 2016, p.581.

24.LI, L., CHEN, Y., WANG, Y., SHI, F., NIE, Y., LIU, T., SONG K., Int. J. Biol. Macromol., 1 (128), 2019, p. 184.

25.SARMAH, P., SARMA, A., KASHYAP, D., MAHANTA, M., AND MEDHI, P., Ann. Plant Sci., 3 (08), 2014 , p. 779.

26.ACEVAL ARRIOLA,N.D., MATTOS DE MEDEIROS, P., PRUDENCIO,E.S., MULLER, C.M.O., DIAS DE MELLO, R., AMBONI, C. Food Biosci., 13 (1), 2016, p.32.

Manuscript received: 11.09 .2019 